\title{
Results Concerning the Influence of the Plant Density and Fertilization on the Sunflower Hybrids Density (Helianthus annuus)
}

\author{
Florentina EREMIA ${ }^{1^{*}}$, Costică CIONTU ${ }^{1}$ \\ 1) University of Agronomic Science and Veterinary Medicine, 59 Marasti, sector 1, 011464, Bucharest, \\ Romania, \\ * corresponding author: eremiaflorentina@yahoo.com \\ Bulletin USAMV series Agriculture 72(1)/2015 \\ Print ISSN 1843-5246; Electronic ISSN 1843-5386 \\ DOI 10.15835/buasvmcn-agr: 11150
}

\begin{abstract}
The main goal of this research theme is to find the best sunflower hybrids (Helianthus annuus) suitable for the South area of Romania, which in various fertilization and technology conditions can give high and stable yields. Crop management was performed in optimal technology, specific to the area of culture, not irrigated variant, the researched genotypes consisting in three hybrids: Performer (control), Barolo R0, and PR64A89. The experiment was placed on a uniform land concerning the fertility and the landscape, on a chernozem soil, in an experimental field belonging to NARDI Fundulea. The conclusions consist in detecting the associated influence of two culture factors, respectively the plant density and fertilization, on the sunflower yield in the climatic conditions of the year 2012.
\end{abstract}

Keywords: density, fertilization, Helianthus annuus, yield.

\section{INTRODUCTION}

Sunflower (Helianthus annuus) is one of the most valuable cultivated plant

due to very high productivity and multiple uses of its products in human alimentation, livestock breeding and industry. In the last decade, due to the application of more efficient technologies and obtaining of new hybrids, the sunflower yield considerably increased in some countries, even spectacular.

Worldwide sunflower has an important place in surface terms, being surpassed only by wheat, rice and maize.

Because of the importance of favorable economic conditions, sunflower still holds an important place in our country's agriculture.
The average yield per hectare at national level depends very much on the evolution of the climatic conditions and soil natural fertility (Bîlteanu, 2003).

Efficient use of natural resources for sunflower yield, in order to be cost-efficient, requires rigorous zoning hybrids, depending on climatic resources and their biological requirements (Hera et al,1989).

The approached issues covered research objectives aimed at optimizing the culture technology in order to achieve maximum and constant sunflower yield, in the soil and climate conditions of southern Romania, also pursuing the economic efficiency and environment protection. 
The objectives in the research were:

- Identify the productivity level influenced by different tillage methods;

- Identify the best sunflower hybrids for the south of Romania, that in different fertilization and technology to determine the achievement of high and stable yields;

- Determining the economic costs and savings generated by judicious choice of hybrid and technological links for sunflower;

- $\quad$ Determining the influence of technological links on yield quality;

- The formulation of practical recommendations for the conditions in South Romania, as well as other areas of similar characteristics.

\section{MATERIALS AND METHODS}

Research were performed in the experimental field Systems of Sustainable Agriculture and Crops Fertilization (SSA-CF) not irrigated version, in the framework of NARDI Fundulea, pursuing the following parameters:

A. Hybrids

- a1 - Performer

- a2 - KWS Barolo RO

- a3 - PR64A89

B. Fertilization

- b1 - unfertilized

- b2 $-\mathrm{N}_{100} \mathrm{P}_{50}$

- b3 -20 t/ha manure (applied to prior culture)

C. Plants density

- c1 - 50.000 plants/ha

- c2-60.000 plants/ha

The experimental diagram is three factorial type of form $3 \times 3 \times 2$, managed according to the subdivided parcels method, in three repetitions. The experimental diagram is three factorial type of form $3 \times 3 \times 2$, arranged according to the method of subdivided parcels, in three repetitions. The experimental results were statistically processed using the variance analysis method (Gologan et al. 1981).

The experiment was placed on a uniform land, concerning the fertility and landscape, chernozem soil, specific to the experimentation area. The previous crop was wheat in all the years of experimentation.

The total testing area was of $11,760 \mathrm{~m}^{2}$. The total area for the experimental plot was of $168 \mathrm{~m}^{2}$, and the yielding area of $112 \mathrm{~m}^{2}$.
In order to organize the experiment it was used biological material consisting of three sunflower hybrids. Crop management was performed in optimal conditions of technology specific to the culture area, the studied genotypes consisting of: Performer (test check - semi-late hybrid), Barolo RO (semi-late hybrid), and PR64A89 (semi-late hybrid).

» Performer. Simple interlinear hybrid, having a good ecologic plasticity, from the precocity group C.

Benefits: very high oil content, 51-53\%, production potential $3,800-4,000 \mathrm{~kg} / \mathrm{ha}$.

Morphophysiological description: tall stature $170-180 \mathrm{~cm}$, large and compact florescence, seed of black color and of ovoid-oblong shape, vegetation period of 114-118 days and a flowering period of 4-5 days. Weight of 1000 grains is 63-78g.

Recommendations: sunflower cultivation in all the favorable areas, including in those affected by broomrape (Orobanche cumana) even in the case of race $\mathrm{E}$.

" Barolo RO. The hybrid is simple, semi-late, (119 days), with a good ecologic plasticity.

Benefits: higher production capability 3,600 - 4,100 kg/ha, very high oil content (49-50\%), good tolerance to drought, good resistance against breakage.

Morphophysiological description: tall stature, abundant green foliage, large capitulum, convex, with pendulum position, well covered by seeds, genetic resistance against broomrape (Orobanche cumana) including the race $\mathrm{E}$.

Recommendations: densities of 45.000$48.000 \mathrm{pl} /$ ha-not irrigated and 50,000-52,000 $\mathrm{pl} /$ ha-irrigated; cultivated in all the favorable areas for sunflower, including in those affected by broomrape, race $\mathrm{E}$.

»PR64A89. The hybrid is simple, semi-late, with a good ecologic plasticity and tolerance against broomrape Race E.

Benefits: genetic resistance against blight attack (Plasmopara helianti) race 304; good tolerance against the Phomopsis Stem Canker caused by the pathogen Phomopsis helianthi; tolerant to stem rot caused by Sclerotinia sclerotiorum; good resistance against drought and heat.

Morphophysiological description: tall stature, abundant dark green foliage, large capitulum, convex, with pendulum position, well covered 
by seeds, seeds of medium size with 1000 seeds weight $65 \mathrm{~g}$ and hectoliter mass (HM) $40-43 \mathrm{~kg} / \mathrm{hl}$, average content of oil 46-47\% (*Varieties/hybrids Official catalog of Romania, 2010).

Recommendation: cultivated in all areas of the sunflower crop in Romania, even in areas infested with broomrape race E; densities of 50-52.000 yielded plants/ha, not irrigated, and 52-55.000 yielded plants /ha, irrigated.

\section{RESULTS AND DISCUSSION}

Processing of the primary data was performed in 2012, by weighing the yield of each variant. It consisted in elimination of studied repetition, achieving the average variation, and reduction the losses and impurities and then reporting at unit area. Variance analysis shows which of the factors or combinations are of higher concern in statistical terms, which will be added to practice or scientific importance of those factors.

This way it was established the most suitable way of using the obtained data in order to make the final conclusions. So, variance analysis concerning the influence of the plant density, fertilization, and hybrid on yield at sunflower is shown in the tables below, ascertaining significant differences both for each factor individually and their interaction, irrespectively for the plant density $\mathrm{x}$ hybrid, fertilization $\mathrm{x}$ hybrid, and plant density $\mathrm{x}$ fertilization x hybrid (Tab. 1 and 2).

Tab.1. Analysis of variance concerning the influence of hybrid, fertilization, and density on sunflower yield

\begin{tabular}{|c|c|c|c|c|c|c|c|}
\hline \multirow{2}{*}{ Variant } & \multirow{2}{*}{ SP } & \multirow{2}{*}{ GL } & \multirow{2}{*}{$S^{2}$} & \multirow{2}{*}{$\mathrm{F}_{\mathrm{C}}$} & \multicolumn{2}{|c|}{$\mathrm{Ft}$} & \multirow[t]{2}{*}{ Significance } \\
\hline & & & & & $5 \%$ & $1 \%$ & \\
\hline A & 1046855 & 2 & 523427.6 & 4.76 & 6.94 & 18.00 & $* *$ \\
\hline E. & 439587.6 & 4 & 109896.9 & & & & \\
\hline $\mathrm{B}^{\mathrm{A}}$ & 2242190 & 2 & 1121095 & 14.59 & 6.94 & 18.00 & $*$ \\
\hline$A \times B$ & 113557.4 & 4 & 28389.3 & 0.37 & 3.26 & 5.41 & $* *$ \\
\hline $\mathrm{E}_{\mathrm{B}}$ & 922182.9 & 12 & 76848.5 & & & & \\
\hline $\mathrm{C}$ & 315875.6 & 1 & 315875.6 & 73.90 & 4.41 & 8.28 & \\
\hline $\mathrm{AxC}$ & 55267.56 & 2 & 27633.7 & 6.46 & 3.55 & 6.01 & $*$ \\
\hline $\mathrm{B} \times \mathrm{C}$ & 15402.69 & 2 & 7701.34 & 1.80 & 3.5 & 6.01 & $* *$ \\
\hline $\mathrm{AxBxC}$ & 44579.44 & 4 & 11144.86 & 2.61 & 2.93 & 4.58 & $* *$ \\
\hline $\mathrm{E}$ & 76938.88 & 18 & 4274.3 & & & & \\
\hline
\end{tabular}

Tab. 2. Analysis of variance proposed for the factors interaction and obtained values for T and LSD

\begin{tabular}{cccccccc}
\hline $\begin{array}{c}\text { Interaction of } \\
\text { factors }\end{array}$ & SD & T 5\% & T 1\% & T 0.1\% & LSD 5\% & LSD 1\% & LSD 0.1\% \\
\hline A to A & 110.50 & 2.78 & 4.60 & 8.61 & 307.20 & 508.31 & 951.43 \\
\hline B to B & 92.41 & 2.18 & 3.06 & 4.32 & 201.44 & 282.76 & 399.19 \\
\hline C to C & 17.79 & 2.10 & 2.88 & 3.92 & 37.37 & 51.25 & 69.75 \\
\hline B to A & 191.40 & 2.18 & 3.06 & 4.32 & 417.24 & 585.67 & 826.83 \\
\hline A to b & 171.14 & 2.43 & 3.70 & 6.11 & 415.89 & 633.56 & 1045.41 \\
\hline C to A & 30.82 & 2.10 & 2.88 & 3.92 & 64.72 & 88.76 & 120.81 \\
\hline C to b & 30.82 & 2.10 & 2.88 & 3.92 & 64.72 & 88.76 & 120.81 \\
\hline B to C & 94.94 & 2.18 & 3.05 & 4.30 & 206.57 & 289.62 & 408.14 \\
\hline A to C & 112.63 & 2.75 & 4.54 & 8.43 & 310.25 & 510.85 & 949.97 \\
\hline $\mathrm{C}$ to A and B & 53.38 & 2.10 & 2.88 & 3.92 & 112.10 & 153.74 & 209.26 \\
\hline B to A and C & 164.44 & 2.18 & 3.05 & 4.30 & 357.79 & 501.63 & 706.92 \\
\hline A to B and C & 175.25 & 2.41 & 3.66 & 6.01 & 423.20 & 642.11 & 1052.74 \\
\hline
\end{tabular}


In table 3 is shown the hybrid influence on the sunflower yield. The obtained data show a relatively low difference of the hybrids. The highest yield of $2,188 \mathrm{~kg} / \mathrm{ha}$ was cropped at the hybrid PR64A89.

The use of the hybrid Barolo RO a leaded to a yield of 2,056 kg/ha, compared to the control Performer where it was yielded $1,850 \mathrm{~kg} / \mathrm{ha}$, the difference wasn't significant. The influence of the crop fertilization on sunflower yield in the condition of the year 2012 is shown in the table 4 Applying to the previous culture of a $20 \mathrm{t} / \mathrm{ha}$ manure, brought a yield increase of $2,244 \mathrm{~kg} /$ ha, corporately to the not fertilized control of $1,757 \mathrm{~kg} / \mathrm{ha}$. The production differences are very significant or distinct significant by comparison to the control.

In the next table (Tab. 5) is shown the influence of plant density on sunflower yield. The use of a

Tab. 3. Influence of factor A (hybrid) on sunflower yield (kg/ha)

\begin{tabular}{|c|c|c|c|c|}
\hline Variant & Average & $\%$ & Difference & Significance \\
\hline a 1 & 1850.28 & 100.00 & & \\
\hline a 2 & 2056.67 & 111.15 & 206.389 & - \\
\hline a 3 & 2188.61 & 118.29 & 338.333 & $\mathrm{x}$ \\
\hline & $\operatorname{LSD}(P 5 \%) \quad 307.20$ & LSD(P 1\%) 508.31 & $\operatorname{LSD}(\mathrm{P} 0.1 \%) \quad 951.43$ & \\
\hline
\end{tabular}

Tab. 4. Influence of factor B (crop fertilization) on sunflower yield (kg/ha)

\begin{tabular}{ccccc}
\hline Variant & Average & $\%$ & Difference & Significance \\
\hline b 1 & 1757.22 & 100.00 & & \\
\hline b 2 & 2093.56 & 119.14 & 336.333 & xx \\
\hline b 3 & 2244.78 & 127.75 & 487.556 & xxx \\
\hline & LSD(P 5\%) 201.44 & LSD(P 1\%) 282.76 & LSD(P 0.1\%) 399.19 & \\
\hline
\end{tabular}

Tab. 5. Influence of factor C (plant density) on sunflower yield ( $\mathrm{kg} / \mathrm{ha}$ )

\begin{tabular}{cccccc}
\hline Variant & Average & $\%$ & Difference & Significance \\
\hline c 1 & 2108.33 & 100.00 & & \\
\hline$c 2$ & 1955.37 & 92.74 & -152.963 & 000 \\
\hline \multicolumn{7}{c}{ LSD(P 5\%) } & 37.37 & LSD(P 1\%) & 51.25 & LSD(P 0.1\%) & 69.75 & \\
\hline
\end{tabular}

Tab. 6. Influence of factor A (hybrid) on sunflower yield $(\mathrm{kg} / \mathrm{ha}$ ) depending on factor B (crop fertilization)

\begin{tabular}{ccccc}
\hline Variant & Average & $\%$ & Difference & Significance \\
\hline a 1 b 1 & 1566.67 & 100.00 & & \\
\hline a 1 b 2 & 1930.00 & 123.19 & 363.333 & - \\
\hline a 1 b 3 & 2054.17 & 131.12 & 487.500 & x \\
\hline a 2 b 1 & 1830.00 & 116.81 & 263.333 & - \\
\hline a 2 b 2 & 2031.67 & 129.68 & 465.000 & x \\
\hline a 2 b 3 & 2308.33 & 147.34 & 741.667 & - \\
\hline a 3 b 1 & 1875.00 & 119.68 & 308.333 & $\mathrm{xx}$ \\
\hline a 3 b 2 & 2319.00 & 148.02 & 752.333 & \\
\hline a 3 b 3 & 2371.83 & 151.39 & 805.167 & \\
\hline
\end{tabular}


50,000 plant/ha density, resulted a yield of 2,108 $\mathrm{kg} / \mathrm{ha}$, variant used as control.

A plant density of $60,000 /$ ha caused a very significant yield decrease of $152 \mathrm{~kg} / \mathrm{ha}$.

The organic fertilization and hybrid associated influence on sunflower yield is shown in table 6, resulting that the highest yields were obtained by applying $20 \mathrm{t} /$ ha manure, no matter the used hybrid.

Replacing organic fertilization with 20 t/ha manure with the fertilization with $\mathrm{N}_{100} \mathrm{P}_{50}$ or not fertilized, cased the yield of productions 363-487 $\mathrm{kg} / \mathrm{h}$ a poorer at the hybrid Performer, $465-741 \mathrm{~kg} /$ ha at Barolo RO, and $752-805 \mathrm{~kg} / \mathrm{ha}$ at the hybrid PR64A89. In all the fertilization variants, using of the hybrid PR64A89 increased the production very significant.

The associated influence of plant density and used hybrid on sunflower yield in the conditions of the year 2012 is shown in the table 7. Out of the obtained data it results the superiority of the variant with the plant density of $50,000 /$ ha by comparison with the variant with the plant density of $60,000 /$ ha, at all cultivated hybrids. Differences from the variant with the plant density of $60,000 /$ ha are significant.
The associates influence of fertilization and density on sunflower yield in conditions of 2012 is shown in the table 8. Out of the shown data it results the higher yields were obtained by fertilizing with $20 \mathrm{t} /$ ha manure and using a density of 50,000 plants/ha. The fertilization with $\mathrm{N}_{100} \mathrm{P}_{70}$ or the lack of fertilization caused yields 350-520 $\mathrm{kg} / \mathrm{h}$ a lower.

\section{CONCLUSION}

Synthesis of data for 2012 concerning the influence of crop fertilization on sunflower yield depending on plant density and the used hybrid is shown in the tables 9 and 10 .

By applying organic fertilization, on the background of using two densities and three hybrids, it results:

- the highest yield were obtained at the organic fertilization of $20 \mathrm{t}$ manure $/ \mathrm{ha}(2,054 \mathrm{~kg} / \mathrm{ha}$, respectively 2,308 $\mathrm{kg} / \mathrm{ha}$, and $2,371 \mathrm{~kg} / \mathrm{ha}$ );

- concerning the plant density, the best variant was of 50,000 plants/ha, no matter the used hybrid.

Analyzing the interaction of all studied factors, we can notice a decrease of production at all three used hybrids (Performer, Barolo RO, and PR64A89) in the unfertilized variant, with

Tab. 7. Influence of factor A (hybrid) on sunflower yield (kg/ha) depending on factor C (plant density)

\begin{tabular}{|c|c|c|c|c|}
\hline Variant & Average & $\%$ & Difference & Significance \\
\hline a 1 c 2 & 1754.44 & 100.00 & & \\
\hline a $1 \mathrm{c} 1$ & 1946.11 & 110.92 & 191.667 & - \\
\hline $\mathrm{a} 2 \mathrm{c} 1$ & 2158.89 & 123.05 & 404.444 & $x$ \\
\hline $\mathrm{a} 2 \mathrm{c} 2$ & 1954.44 & 111.40 & 200.000 & - \\
\hline a $3 c 1$ & 2220.00 & 126.54 & 465.556 & $x$ \\
\hline \multirow{2}{*}{ a $3 c 2$} & 2157.22 & 122.96 & 402.778 & $x$ \\
\hline & LSD(P 5\%) 310.25 & LSD(P 1\%) 510.85 & LSD(P 0.1\%) 949.97 & \\
\hline
\end{tabular}

Tab. 8. Influence of factor B (fertilization) on sunflower yield (kg/ha) depending on factor C (plant density)

\begin{tabular}{ccccc}
\hline Variant & Average & $\%$ & Difference & Significance \\
\hline b 1 c 1 & 1810.00 & 100.00 & & - \\
\hline b 1 c 2 & 1704.44 & 94.17 & $-105,556$ & xx \\
\hline b 2 c 1 & 2184.44 & 120.69 & 374,444 & - \\
\hline b 2 c 2 & 2002.67 & 110.64 & 192,667 & xxx \\
\hline b 3 c 1 & 2330.56 & 128.76 & 520,556 & xx \\
\hline b 3 c 2 & 2159.00 & 119.28 & 349,000 & LSD 0.1\%=408.14 \\
\hline
\end{tabular}


statistical values as significant or very significant, ranging between $200-1,600 \mathrm{~kg} / \mathrm{ha}$ (Fig. 1).

Concerning the hybrids reaction at the interaction of the studied factors, we can see they have a similar behavior, the yields being comparable depending on the applied technology. Taking into account the studied variants, the culture of sunflower consists in fertilizing with

Tab. 9. Influence of factor B (fertilization) on sunflower yield ( $\mathrm{kg} / \mathrm{ha}$ ) depending on hybrid plant density

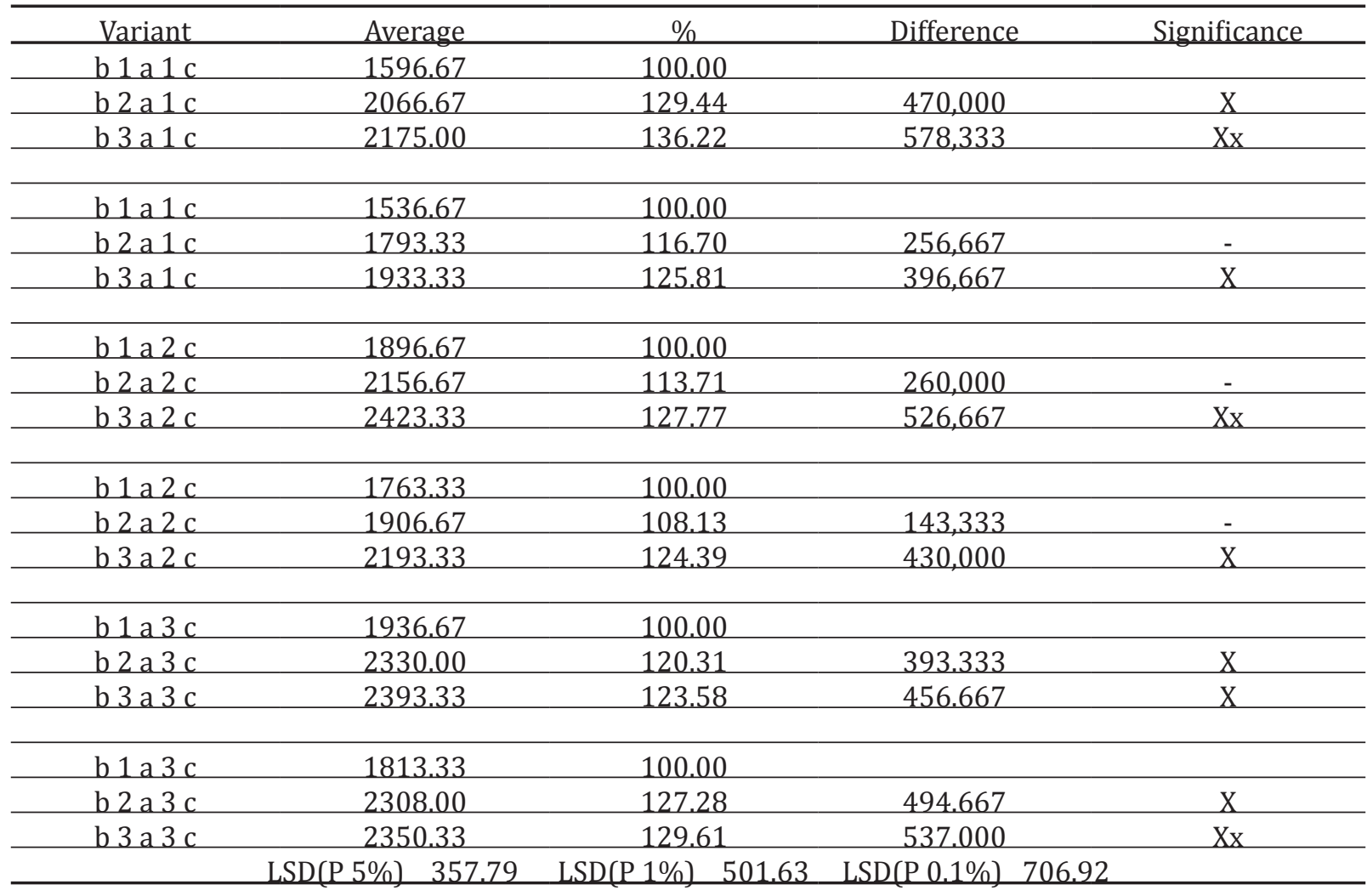

Tab. 10. Influence of hybrid, crop fertilization and plant density on average sunflower yield (kg/ha)

\begin{tabular}{|c|c|c|c|c|}
\hline \multicolumn{2}{|c|}{ Variant } & C & $\mathrm{C}$ & Average vield \\
\hline \multirow{3}{*}{$A_{1}$} & B & 1596 & 1536 & 1566 \\
\hline & $\mathrm{B}_{2}$ & 2066 & 1793 & 1930 \\
\hline & $\mathrm{B}^{2}$ & 2175 & 1933 & 2054 \\
\hline \multirow{3}{*}{$\mathrm{A}_{2}$} & $B^{3}$ & 1896 & 1763 & 1830 \\
\hline & $\mathrm{B}_{2}$ & 2156 & 1906 & 2031 \\
\hline & $B_{3}^{2}$ & 2423 & 2193 & 2308 \\
\hline \multirow{3}{*}{$\mathrm{A}_{3}$} & $B_{1}^{3}$ & 1936 & 1813 & 1875 \\
\hline & $B$ & 2330 & 2308 & 2319 \\
\hline & $\mathrm{B}_{3}^{2}$ & 2393 & 2350 & 2371 \\
\hline Ar & & 2108 & 1955 & 2032 \\
\hline
\end{tabular}




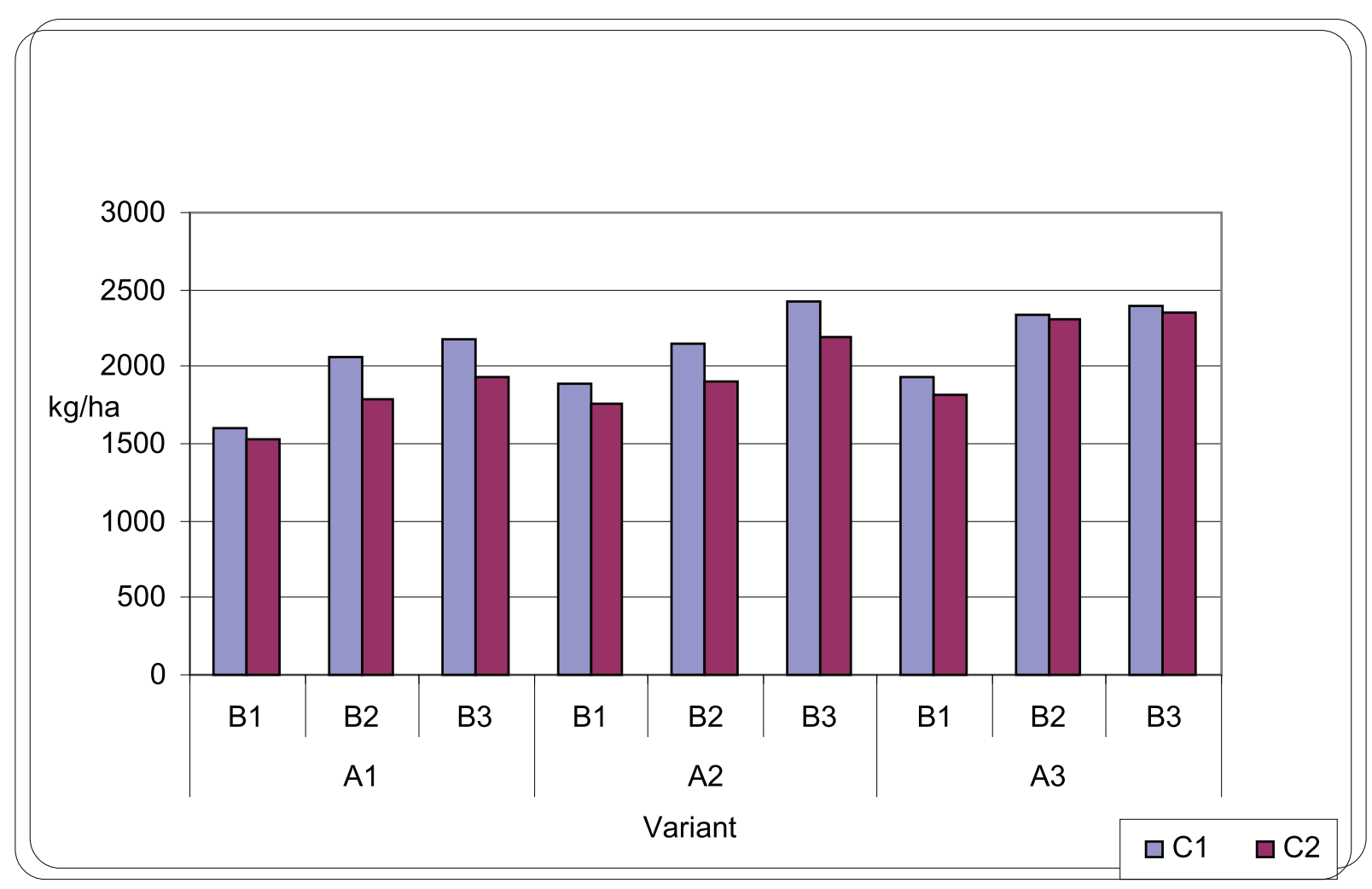

Fig. 1. Influence of hybrid, crop fertilization and plant density on sunflower yield (kg/ha)

20 t/ha manure, using a density of 50,000 plants/ha, and using of the hybrid PR64A89. This recommended technology is useful in the case of an agricultural year similar to 2012 .

\section{REFERENCES}

1. Bîlteanu Gh (2003). Phytotechnics. Ceres Publishing House, Bucharest 2:13-61.

2. Gologan I, Dornescu A (1981). Plant Breeding Course. Agronomy Institute Ion Ionescu de la Brad, Iasi:350.

3. Ion V, Hălmăjan HV(2001). Sunflower yielding, storing and preserving the yield. Journal of Cereals and technical crops 8:1-5.

4. Ion V, Ion N, Roman GV, Bucată LI, Dumbravă M, Iștoc VA (2004). Behavior of Romanian sunflower hybrids in the meteorological conditions of 2002, on the reddish-brown soil from Moara Domnească. Scientific Papers, USAMV Bucharest Agronomy Series A (XLVI)

5. Ion V, Ştefan V, Ion N, Roman GV, Dumbravă M (2006). Data on flowering to an assortment of foreign hybrids of sunflower admitted for cultivation in Romania. Scientific Papers, International Symposium of Apiculture
"Sustainable management beekeeping exploitations in compliance with EU requirements", Tulcea, 7-8 of September.

6. Hera C, Sin G, Toncea I (1989). Sunflower crop. Ceres Publishing House, Bucharest.

7. ${ }^{* * *}(2010)$.Varieties/hybrids Official catalog of Romania. 